\title{
Formation and growth of sub-3 nm particles in megacities : impact of background aerosols
}

\section{Deng, Chenjuan}

2021-03-01

Deng , C , Cai , R , Yan , C , Zheng , J \& Jiang , J 2021 , ' Formation and growth of sub-3 nm particles in megacities : impact of background aerosols ' , Faraday Discussions, vol. 226 , pp. 348-363 . https://doi.org/10.1039/D0FD00083C

http://hdl.handle.net/10138/337903

https://doi.org/10.1039/D0FD00083C

unspecified

acceptedVersion

Downloaded from Helda, University of Helsinki institutional repository.

This is an electronic reprint of the original article.

This reprint may differ from the original in pagination and typographic detail.

Please cite the original version. 


\title{
Formation and growth of sub-3 nm particles in megacities: impacts of background aerosols
}

\author{
Chenjuan Denga ${ }^{\mathrm{a}}$, Runlong Cai ${ }^{\mathrm{b}}$, Chao Yan ${ }^{\mathrm{b}, \mathrm{c}}$, Jun Zheng ${ }^{\mathrm{d}}$, and Jingkun Jianga,* \\ ${ }^{a}$ State Key Joint Laboratory of Environment Simulation and Pollution Control, School of Environment, Tsinghua \\ University, 100084 Beijing, China
}

${ }^{b}$ Institute for Atmospheric and Earth System Research/Physics, Faculty of Science, University of Helsinki, 00014 Helsinki, Finland

${ }^{c}$ Aerosol and Haze Laboratory, Beijing Advanced Innovation Center for Soft Matter Science and Engineering, Beijing University of Chemical Technology, 100029 Beijing, China

${ }^{d}$ Collaborative Innovation Center of Atmospheric Environment and Equipment Technology, Nanjing University of Information Science and Technology, 210044 Nanjing, China

* Correspondence to: J. Jiang (jiangjk@tsinghua.edu.cn)

\begin{abstract}
New particle formation (NPF) occurs frequently in various atmospheric environments and contributes majorly to the aerosol number budget. In megacities, the high concentration of background aerosols adds uniqueness to this process. Based on long-term measurements (373 days) in urban Beijing, we examine the formation and growth of sub-3 nm particles under the impacts of background aerosols, as indicated by the condensation sink (CS, or the Fuchs surface area). The median CS and the median $\mathrm{PM}_{2.5}$ mass concentration for these days were $0.03 \mathrm{~s}^{-1}$ and $34 \mu \mathrm{g} / \mathrm{m}^{3}$, respectively. The high loss rate to background aerosols suppresses the survival of both molecular clusters and sub-3 $\mathrm{nm}$ particles, thus reduces their atmospheric residence time. As the key clusters for $\mathrm{H}_{2} \mathrm{SO}_{4}$-base nucleation, sulfuric acid dimer and trimer concentrations in Beijing decrease significantly when CS increases and the scavenging becomes stronger. The formation of sub-3 nm particles and the occurrence of NPF events in Beijing is governed by CS. 96\% of the observed NPF days occurred with the CS value below $0.03 \mathrm{~s}^{-1}$. During NPF events in Beijing, high concentrations of sub-3 nm particles were formed and they mostly ranged from $10^{3}$ to $10^{5} \mathrm{~cm}^{-3}$ with a median value of $6.3 \times 10^{3} \mathrm{~cm}^{-3}$. Driven by the fast $\mathrm{H}_{2} \mathrm{SO}_{4}$-base nucleation, the formation rate of $1.5 \mathrm{~nm}$ particles in Beijing with a mean value of $67 \mathrm{~cm}^{-3} \mathrm{~s}^{-1}$ is much higher than that in clean environments. However, the mean growth rate of sub-3 $\mathrm{nm}$ particles in Beijing was only $2.7 \mathrm{~nm} / \mathrm{h}$, not significantly different from that in clean environments. The relatively low growth rate and the high scavenging by background aerosols result in a low survival of newly formed particles. Note that conventional methods to quantify the formation rate and the growth rate need to be corrected when analyzing data from megacities with strong coagulation scavenging due to background aerosols. The conventional balance formula underestimates the formation rate of $1.5 \mathrm{~nm}$ particles, while the conventional appearance time
\end{abstract}


method overestimates the growth rate of sub-3 nm particles. These findings highlight the governing role of background aerosols in urban NPF.

\section{Introduction}

New particle formation (NPF) is a frequent phenomenon that has been observed in various atmospheric environments around the world ${ }^{1,2}$. During an atmospheric NPF event, gaseous precursors form new particles via nucleation, as characterized by a significant increase in the concentration of sub-3 nm particles. After the growth, these new particles can contribute to the cloud condensation nuclei and hence impact the climate ${ }^{3,4}$. They can also contribute to the aerosol surface area concentration and hence participate heterogeneous physicochemical processes in the atmosphere. Due to the coagulation scavenging by background aerosols, however, only a fraction of newly formed sub-3 nm particles survive and grow into larger ones. In polluted urban environments (often with high concentration of background aerosols), the scavenging rate is high. For instance, the coagulation loss rate of new particles in megacities such as Beijing ${ }^{5,6}$ was reported to be approximately one order of magnitude higher than that in the Finnish boreal forest ${ }^{7}$. Background aerosols also suppress the survival of gaseous precursors and molecular clusters.

The importance of atmospheric background aerosols to the formation and growth of sub-3 nm particles has been theoretically analyzed since decades $\mathrm{ago}^{8}$. The scavenging rate of precursors, clusters, and newly formed particles is usually characterized by the condensation sink $(\mathrm{CS})^{9}$ or the Fuchs surface area $\left(A_{\text {Fuchs }}\right)^{10}$ of background aerosols. CS and $A_{\text {Fuchs }}$ can be readily converted into each other using an approximately constant ratio. These two parameters are size-independent. They can be readily used to calculate the scavenging rate of particles (species) with a known size. At a given growth rate for newly formed particles, CS (or $A_{\text {Fuchs }}$ ) determines their survival probability ${ }^{11-13}$, e.g., high CS would suppress their survival. Theoretically, sub-3 nm particles can be formed via nucleation, but may not grow fast and large enough to be detected by conventional aerosol instruments.

Directly measuring the size distributions of atmospheric sub-3 $\mathrm{nm}$ particles is a key to characterize the impacts of background aerosols on their formation and growth. Developments of new aerosol instruments extended size distribution measurement to the sub-3 $\mathrm{nm}$ size range ${ }^{14-17}$. In megacities such as Beijing, high concentrations of sub$3 \mathrm{~nm}$ particles often occur during NPF events, which benefits their size distribution measurements ${ }^{18-20}$ compare to clean environments such as Tibet ${ }^{21}$ and the Finnish boreal forest ${ }^{17}$. During a short-term campaign in Beijing using new instruments, $A_{\text {Fuchs }}$ was found to be the governing factor for the occurrence of $\mathrm{NPF}^{19}$. Based on a following longterm measurements, Cai et al. ${ }^{22}$ quantified the impacts of $\mathrm{CS}$ on $\mathrm{H}_{2} \mathrm{SO}_{4}$-amine nucleation, the dominant mechanism in Beijing, and Deng et al. ${ }^{20}$ revealed the governing role of atmospheric temperature in driving the seasonal variation of the formation of $1.5 \mathrm{~nm}$ particles.

In addition, a high concentration of background aerosols poses challenges to quantify the formation rate and the growth rate of new particles from measured aerosol size distributions. Conventional methods developed using data 
from clean environments may underestimate or neglect the strong coagulation scavenging effect encountered in polluted urban environments. For instance, Cai and Jiang ${ }^{18}$ found that the formation rate of $1.5 \mathrm{~nm}$ particles in Beijing is underestimated by the commonly used formulae and derived an improved formula. A following study ${ }^{23}$ showed that the conventional appearance time method overestimates the growth rate of sub-3 nm particles and reported a corrected method. Similar challenges can be encountered when analyzing data from chamber studies ${ }^{24}$. Long-term size distributions of atmospheric sub-3 nm particles help to further evaluate these challenges and the new methods.

In this study, we examine the impacts of background aerosols on the formation and growth of sub- $3 \mathrm{~nm}$ particles in polluted urban environments. Long-term aerosol size distributions down to $\sim 1 \mathrm{~nm}$ obtained in Beijing during 2016 and 2018-2020 are analyzed. Mass concentrations of fine particles $\left(\mathrm{PM}_{2.5}\right)$ and concentrations of sulfuric acid and its clusters are used to complement the analysis. We discuss the impacts of background aerosols on atmospheric residence time of molecular clusters and newly formed particles. The governing role of CS on the occurrence of NPF events and the formation of sub-3 $\mathrm{nm}$ particles in urban environments is revealed. We confirm that conventional methods need to be corrected to properly quantify the formation rate and the growth rate, i.e. two key parameters for characterizing NPF, when the coagulation scavenging effect is strong.

\section{Data used in the analysis}

Atmospheric measurements covering totally 373 days were conducted at two sites in urban Beijing. A short-term campaign ${ }^{18,19}$ was carried out at Tsinghua University during Mar 7 - Apr 6, 2016. Long-term measurements were conducted at the west campus of Beijing University of Chemical Technology ${ }^{20,22,25}$ during Jan 16 - May 17 and Oct 19 - Dec 26, 2018, Jan 1-Mar 28, and Jul 19 - Dec 31, 2019. Details of these two sites and measurement techniques can be found in the cited references. Here, we present them briefly. The aerosol size distributions in the range of 1 $\mathrm{nm}-10 \mu \mathrm{m}$ were measured using a home-made diethylene glycol scanning mobility particle spectrometer (DEG-SMPS; $1-6.5 \mathrm{~nm})^{14,16}$ and a particle size distribution spectrometer (PSD; $\left.3 \mathrm{~nm}-10 \mu \mathrm{m}\right)^{26}$. DEG-SMPS was equipped with a specially designed miniature cylindrical differential mobility analyzer ${ }^{16,27}$ for classifying sub-10 nm particles and a core sampling device ${ }^{28}$ for improving their sampling efficiency. Concentrations of sulfuric acid and its clusters were measured using nitrate chemical ionization-time of flight mass spectrometers (CIMS; Aerodyne Research Inc. $)^{19,25,29} . \mathrm{PM}_{2.5}$ mass concentrations for these periods are from the Wanliu national monitoring station ${ }^{30}$ that is close to these two sites. All the measured days were classified into NPF days, undefined days, and non-NPF days according to the criteria reported previously ${ }^{20}$.

\section{Results and Discussion}

We shall first clarify the notion of background aerosols before discussing their impacts on NPF in megacities. In previous literatures, background aerosols, or named pre-existing aerosols, were usually referred to as large particles that scavenge newly formed particles and they were usually measured by conventional aerosol instruments. These instruments are not effective in measuring the size distributions of sub-3 $\mathrm{nm}$ particles. However, the coagulation among newly formed sub-3 nm particles (self-coagulation) also causes a net loss in their concentration and this can 
be important for some analysis ${ }^{24,31}$. Now with direct measurements down to the cluster size using new aerosol instruments, there is no natural criterion in the size to distinguish newly formed particles and large particles. To minimize this ambiguity, we refer to aerosols existing in the atmosphere before the occurrence of NPF events as preexisting aerosols in contrast to newly formed particles. Background aerosols are referred to all the measured aerosols in the following discussions and CS (and $A_{F u c h s}$ ) is calculated using aerosol size distributions down to $\sim 1.3 \mathrm{~nm}$. This is because the coagulation between a given particle and any other particle contributes to the sink of this given particle, which is consistent with the calculation of particle formation rate using the balance formula ${ }^{18}$ and the correction of particle growth rate $^{23}$. Note that the diameter reported in this study refers to the electrical mobility diameter which is $\sim 0.3 \mathrm{~nm}$ larger than the corresponding geometric diameter ${ }^{32,33}$.

\subsection{Atmospheric residence time}

The coagulation scavenging by the high concentration of background aerosols in polluted urban environments significantly suppresses the survival of newly formed sub- $3 \mathrm{~nm}$ particles. For these 373 days in Beijing, the CS values ranged from 0.002 to $0.2 \mathrm{~s}^{-1}$ and the median was $0.03 \mathrm{~s}^{-1}$ (Fig. 1a). $\mathrm{PM}_{2.5}$ mass concentration in Beijing correlated with CS very well $(r=0.75)^{19}$. The median $\mathrm{PM}_{2.5}$ concentration during these days was $34 \mu \mathrm{g} / \mathrm{cm}^{3}$ (Fig. 1b). The median CS values for NPF days and non-NPF days were $0.009 \mathrm{~s}^{-1}$ and $0.045 \mathrm{~s}^{-1}$, respectively, corresponding to $\mathrm{PM}_{2.5}$ concentrations of $10 \mu \mathrm{g} / \mathrm{cm}^{3}$ and $60 \mu \mathrm{g} / \mathrm{cm}^{3}$, respectively. Note that the median CS value for NPF days in Beijing is even higher than that for non-NPF days in clean environments such as the Finnish boreal forest $\left(0.007 \mathrm{~s}^{-1}\right)^{7}$.

Considering the scavenging by background aerosols, the residence time of particles smaller than $1.5 \mathrm{~nm}$ was estimated to be mostly below 5 min on NPF days in Beijing (Fig. 1c). On non-NPF days, the residence time is even shorter. The residence time increases rapidly with an increase in particle size because the coagulation loss rate of a particle is inversely correlated to its size with a power of approximately $-1.7^{34}$. Therefore, the coagulation scavenging significantly affects the nucleation and initial growth processes for sub-3 $\mathrm{nm}$ particles in comparison to subsequent growth process (Fig. 1d). This also highlights the importance of directly measuring the size distributions of atmospheric sub-3 nm particles when studying NPF in polluted urban environments.

\section{Fig. 1}

The high scavenging rate of newly formed sub-3 nm particles in polluted urban environments demands the revisit to the nucleation theory. In the classical nucleation theory, condensation and evaporation boosted by the Kelvin effect are considered as the governing processes for the cluster dynamics. A critical cluster size for a nucleating system can be derived according to the phase equilibrium between condensation and evaporation. Once a cluster exceeds the critical cluster size, the condensation rate is higher than the evaporation rate and this cluster is considered as stable and also as a new particle. Various nucleation theories have been proposed, yet most of them implicitly assume that evaporation is the main limiting process ${ }^{35}$. However, the coagulation scavenging by background aerosols also influences the phase equilibrium. Because of the coagulation scavenging, the equilibrium between condensation and evaporation can never be reached in real atmospheric conditions. Instead, it may occur at a steady state between the mass gains of new particles due to condensation and the mass losses due to evaporation and the coagulation 
scavenging. The same applies for molecular clusters. As a result, both evaporation and the coagulation scavenging limit the concentration of new particles and clusters. Under the high CS in polluted urban environments, when a cluster exceeds the critical size, even though it is stable against evaporation, the coagulation scavenging still governs its survival (Fig. 1d).

\subsection{Cluster concentrations}

Measured concentrations of $\mathrm{H}_{2} \mathrm{SO}_{4}$ and its clusters confirm that they are limited by the scavenging to background aerosols in polluted urban environments. As shown in Fig. 2a, CS governs the concentration of $\mathrm{H}_{2} \mathrm{SO}_{4}$ dimers, the cluster containing two $\mathrm{H}_{2} \mathrm{SO}_{4}$ molecules and any number of other molecules. At a given $\mathrm{H}_{2} \mathrm{SO}_{4}$ monomer concentration, $\mathrm{H}_{2} \mathrm{SO}_{4}$ dimer concentration decreases with an increasing CS. This is because the loss to background aerosols is a major sink of $\mathrm{H}_{2} \mathrm{SO}_{4}$ clusters in Beijing. Similarly, a negative dependency of $\mathrm{H}_{2} \mathrm{SO}_{4}$ trimer concentration on CS is also observed at a given formation rate of $\mathrm{H}_{2} \mathrm{SO}_{4}$ trimers (Fig. 2b).

Fig. 2

The differences between the concentrations of $\mathrm{H}_{2} \mathrm{SO}_{4}$ clusters measured in Beijing and those measured in chamber experiments also support the significant impact of background aerosols in polluted urban environments. At the $\mathrm{H}_{2} \mathrm{SO}_{4}$ monomer concentration of $\sim 10^{7} \mathrm{~cm}^{-3}, \mathrm{H}_{2} \mathrm{SO}_{4}$ dimer and trimer concentrations measured in Beijing were $\sim 5 \times 10^{5} \mathrm{~cm}^{-3}$ and $<1 \times 10^{5} \mathrm{~cm}^{-3}$, respectively. In contrast, $\mathrm{H}_{2} \mathrm{SO}_{4}$ dimer and trimer concentrations measured in the Cosmics Leaving OUtdoor Droplets (CLOUD) chamber experiments ${ }^{36}$ at a similar $\mathrm{H}_{2} \mathrm{SO}_{4}$ monomer concentration were $\sim 2 \times 10^{6} \mathrm{~cm}^{-3}$ and $\sim 6 \times 10^{5} \mathrm{~cm}^{-3}$, respectively. These differences in $\mathrm{H}_{2} \mathrm{SO}_{4}$ cluster concentrations are mainly attributed to the high scavenging rate in Beijing in comparison to the low loss rate in CLOUD chamber. Although there are differences in other factors such as amine concentration and temperature between Beijing and CLOUD chamber experiments ${ }^{22}$, they are not sufficient to explain the differences in measured $\mathrm{H}_{2} \mathrm{SO}_{4}$ cluster concentrations because $\mathrm{H}_{2} \mathrm{SO}_{4}$ dimer and trimer are considered to be stable against evaporation ${ }^{37,38}$. After taking uncertainties into account, theoretically predicted $\mathrm{H}_{2} \mathrm{SO}_{4}$ dimer and trimer concentrations with properly considering the scavenging effect by background aerosols agree well with the measured concentrations in Beijing ${ }^{22}$.

It should be clarified that the apparent dependency of $\mathrm{H}_{2} \mathrm{SO}_{4}$ cluster concentrations on CS shown in Fig. 2 also convolves the impact from variations in the concentration of amine such as dimethylamine, the other key nucleating precursor in addition to $\mathrm{H}_{2} \mathrm{SO}_{4}$. Previous studies ${ }^{22,39}$ showed that the clustering of $\mathrm{H}_{2} \mathrm{SO}_{4}$ and dimethylamine governs the formation of new particles in megacities such as Shanghai and Beijing. When other conditions are fixed, $\mathrm{H}_{2} \mathrm{SO}_{4}$ cluster concentrations increase with an increase in amine concentration ${ }^{40,41}$. In Beijing, amine concentration appears to positively correlate with CS, i.e. it is higher when there are more background aerosols $\mathrm{s}^{22}$. As a result, the impact of an increasing $\mathrm{CS}$ on $\mathrm{H}_{2} \mathrm{SO}_{4}$ cluster concentrations in Beijing is partially cancelled out by the simultaneously increasing amine concentration. However, amine concentration is saturated with respect to the formation of $\mathrm{H}_{2} \mathrm{SO}_{4}$ dimer when it exceeds $\sim 5 \mathrm{ppt}^{40}$, i.e. further increasing amine concentration does not increase the formation rate and cluster concentrations significantly. As a result, the apparent dependency of $\mathrm{H}_{2} \mathrm{SO}_{4}$ cluster concentrations on CS is theoretically stronger at a high CS value than at a low CS value, consistent with the observed dependency in Fig. 2. 
3.3 Sub-3 nm particle concentrations and occurrence of NPF events

Both the number concentration of sub-3 nm particles and the occurrence frequency of NPF events in Beijing support that they are limited by the coagulation scavenging of background aerosols (Fig. 3). As shown in Fig. 3a, there is a negative correlation between CS and sub-3 nm particle concentration. When CS is low, frequent NPF events occur and sub-3 nm particle concentrations are often high, i.e. mostly in the range of $10^{3}-10^{5} \mathrm{~cm}^{-3}$ with a median value of $6.3 \times 10^{3} \mathrm{~cm}^{-3}$. When CS is high, sub-3 nm particles are suppressed with their concentrations mostly below $10^{3} \mathrm{~cm}^{-3}$ and a distinguishable NPF event is rarely observed. During NPF days in Beijing, note that sub-3 nm particle concentrations measured by the DEG-SMPS are similar to those measured by a particle size magnifier (PSM) ${ }^{17}$. They are also similar to those in other megacities such as Shanghai and Nanjing and higher than those in clean environments such as the Finnish boreal forest ${ }^{42}$. During non-NPF days in Beijing, however, PSM still reported elevated concentrations ${ }^{17}$ even though sub-3 nm particle concentrations measured by the DEG-SMPS were significantly lower (Fig. 3a).

The concentration of newly formed particles must exceed the concentration of pre-existing aerosols, so that distinguishable NPF events can be observed and identified. We used the $10^{\text {th }}$ percentile of the concentration of nucleation mode particles (sub-25 nm) to indicate a low limit of pre-existing aerosol concentration. As shown in Fig. 3a, measured sub-3 nm particles in Beijing exceeds pre-existing aerosols mainly when CS is lower than $\sim 0.03 \mathrm{~s}^{-1}$.

Fig. 3

Among the 373 days measured in Beijing, NPF events occurred on a total of 121 days. In addition, there were 53 undefined days. When CS is lower than $\sim 0.01 \mathrm{~s}^{-1}$, most of the measured days are NPF days (Fig. 3b). When CS was higher than $\sim 0.03 \mathrm{~s}^{-1}$, non-NPF days are dominant and NPF days are rarely observed. When CS decreases from $0.03 \mathrm{~s}^{-1}$ to $0.01 \mathrm{~s}^{-1}$, the observed NPF days increase. For this transition range of CS, there is a mixture of NPF days, undefined days, and non-NPF days. The $50 \%$ frequency of NPF days corresponds to a CS value of $\sim 0.02 \mathrm{~s}^{-1}$. Note that these threshold values are consistent to the value $\left(\sim 0.02 \mathrm{~s}^{-1}\right)$ previously reported for urban Beijing based on a short-term campaign ${ }^{19}$.

Under the high CS in polluted urban environments, the coagulation scavenging governs the survival of clusters and newly formed particles and hence determines whether distinguishable NPF events will be observed or not. Despite the significant difference in CS during NPF days and non-NPF days in Beijing, the daily maximum concentration of the key nucleating precursor $\mathrm{H}_{2} \mathrm{SO}_{4}$ has no obvious differences during NPF days and non-NPF days ${ }^{19}$, ${ }^{20}$. The other key nucleating precursor dimethylamine correlates well with CS and often has higher concentrations during non-NPF days in comparison to NPF days ${ }^{20,22}$. Thus, $\mathrm{H}_{2} \mathrm{SO}_{4}$ and amine are still effectively clustering with each other during non-NPF days. Because of the high CS on non-NPF days, however, the atmospheric residence time of molecular clusters and newly formed particles is very short (Fig. 1c). This short residence time together with the low growth rate of sub-3 nm particles in Beijing, i.e. rarely exceeds $6 \mathrm{~nm} / \mathrm{h}$, leads to that most of the clusters formed by the acid-base clustering process and most newly formed particles are scavenged by background aerosols before they grow large enough and still have significant quantities to be measured such that distinguishable NPF events can 
be identified on these days.

3.4 Quantifying the formation rate of sub-3 nm particles

All the measured aerosol size distributions during NPF periods were used to evaluate the conventional ${ }^{43}$ and improved ${ }^{18}$ population balance formulae for quantifying particle formation rate $(J)$. Several upper size limits were used. The formation rates of $1.5 \mathrm{~nm}$ particles calculated using different formulae are referred as $J_{\mathrm{C}, 25}, J_{\mathrm{C}, 10}, J_{\mathrm{K}, 25}$, and $J_{\mathrm{K}, 3}$. The former two were calculated using the improved formula while the latter two were calculated using the conventional formula. The number in the subscript of $J$ indicates the upper size limit (in nm) used for the estimation. In these formulae, coagulation sink term (CoagSnk) characterizes the coagulation scavenging. One example of CoagSnk $\mathrm{C}_{\mathrm{C} 10}$ is shown in Fig. $4 \mathrm{a}$ together with the corresponding formation rate $J_{\mathrm{C}, 10}$. Details of these formulae and their differences can be found in the cited reference ${ }^{18}$.

\section{Fig. 4}

The calculated formation rate in Beijing is governed by coagulation sink term, especially during intensive NPF events. This is due to the high concentrations of background aerosols including newly formed small particles in these polluted environments. As show in Fig. $4 \mathrm{a}$, the ratio of $\mathrm{CoagSnk}_{\mathrm{C}, 10}$ to $J_{\mathrm{C}, 10}$ is $\sim 1$ in Beijing. This indicates that from the population balance point of view, most of the new particles are scavenged by coagulation while only a minor proportion of them survive and further grow into larger ones. Hence, CoagSnk needs to be carefully quantified when estimating $J$ for polluted urban environments using a population balance method. At a given level of background aerosols, small particles (e.g. sub-3 nm) usually contribute more significantly to CoagSnk than large ones. This is because small particles have higher diffusivity and often higher number concentration during NPF periods. As a result, the estimated $J$ value is not sensitive to the upper size limit for a certain particle size range. As illustrated previously ${ }^{18}$, the upper size limit should be chosen such that the growth flux through the upper size limit and the impact of other sources of particles (e.g. primary emission) in the selected size range are both negligible compared to the value of $J$. Figs. $4 \mathrm{a}$ and $4 \mathrm{~d}$ show a good agreement between $J_{\mathrm{C}, 10}$ and $J_{\mathrm{C}, 25}$, i.e. with the upper size limit of $10 \mathrm{~nm}$ and $25 \mathrm{~nm}$, respectively. The absolute and relative differences between them for this long-term dataset are $0.4 \mathrm{~cm}^{-3} \mathrm{~s}^{-1}$ and $2 \%$, respectively. Fig. $4 \mathrm{~d}$ also shows that before the NPF period (around $8 \mathrm{am}$ ), those pre-existing particles in the size range of 10 to $25 \mathrm{~nm}$ can be mistaken as new particles when using the upper size limit of $25 \mathrm{~nm}$. However, this does not cause a noticeable difference between $J_{\mathrm{C}, 25}$ and $J_{\mathrm{C}, 10}$.

The conventional formula underestimates $J$ during intensive NPF events due to the underestimation of CoagSnk. When calculating CoagSnk using the conventional formula, the diffusivities of particles in the selected size range are approximated by the diffusivity of the particle at a representative size, for which the geometric mean size of the selected size range is often used ${ }^{43}$. Due to the significant size dependency of particle diffusivity, such an approximation usually underestimates CoagSnk and hence $J$. Other differences between the improved and conventional formulae have been elaborated previously ${ }^{18}$. As indicated in Figs. $4 \mathrm{~b}$ and $4 \mathrm{~d}, J_{\mathrm{K}, 25}$ calculated from the conventional formula is significantly lower than $J_{\mathrm{C}, 10}$ and $J_{\mathrm{C}, 25}$ during intensive NPF events ( $J$ is high). In contrast, $J_{\mathrm{K}, 25}$ is averagely close to $J_{\mathrm{C}, 10}$ during weak and moderate NPF events $\left(J<10 \mathrm{~cm}^{-3} \mathrm{~s}^{-1}\right)$ when CoagSnk is not the 
governing term of $J$.

The above analysis using the long-term dataset in Beijing confirms that although the approximation in the conventional formula does not cause significant uncertainty for clean environments with low $J$, one should use the improved formula for polluted environments. Reducing the upper size limit from $25 \mathrm{~nm}$ to $3 \mathrm{~nm}$ for the conventional formula improves the estimation of $J$, especially during intensive NPF events (Figs. $4 b$ and $4 c$ ). This is because the deviations caused by the representative-size-approximation are reduced when using a narrow size range (1.5-3 nm) than a wide size range $(1.5-25 \mathrm{~nm})$. As shown in Figs. $4 \mathrm{c}$ and $4 \mathrm{~d}$, however, $J_{\mathrm{K}, 3}$ with the upper size limit of $3 \mathrm{~nm}$ still underestimates the formation rate of $1.5 \mathrm{~nm}$ particles.

3.5 Quantifying the growth rate of sub-3 $\mathrm{nm}$ particles

The high CS in polluted urban environments also affects the estimation of particle growth rate. This long-term dataset in Beijing was used to evaluate the conventiona ${ }^{44}$ and corrected ${ }^{23}$ appearance time methods for quantifying the growth rate of sub-3 nm particles. As shown in Fig. 5, the conventional appearance time method non-negligibly overestimates the growth rate from 1.5 to $3 \mathrm{~nm}\left(\mathrm{GR}_{1.5-3}\right)$. This is because the appearance time is determined by the source and sink of particles at a given size, while the sink herein includes both particle condensation growth and coagulation sink. However, the conventional appearance time method was proposed based on clean environments with negligible coagulation scavenging. The mean coagulation sink of $1.5 \mathrm{~nm}$ particle for this long-term dataset in Beijing is $\sim 2.5 \times 10^{-3} \mathrm{~s}^{-1}$, which corresponds to an average overestimation in $\mathrm{GR}_{1.5-3}$ by $0.7 \mathrm{~nm} / \mathrm{h}$ when using the conventional appearance time method. As shown in Fig. 5, the overestimation by the conventional method becomes more significant when CS increases. In contrast, such an overestimation appears to be negligible in clean environments due to their low CS.

\section{Fig. 5}

In addition, other methods such as the mode fitting method ${ }^{43,45}$ have also been used for quantifying particle growth rate. Each method has its advantages in certain scenarios. Results from different methods don't necessarily agree with each other, especially when analyzing atmospheric data. For instance, Deng et al. ${ }^{20}$ showed that $\mathrm{GR}_{1.5-3}$ in Beijing calculated by the corrected appearance time method is $2 \sim 3$ times higher than that by the mode fitting method. The inherent fluctuations in the atmosphere add challenges in analyzing field data in comparison to those from chamber experiments. On the other hand, cautions should be taken on whether sinks such as wall deposition in chamber experiments ${ }^{46}$ (besides the coagulation sink corrected here) may affect the estimation using the appearance time method. Nevertheless, the corrected appearance time method is more suitable for atmospheric sub-3 nm particles than the mode fitting method since there is often no peaks in their size distributions as needed by the fitting method.

3.6 The formation rate and the growth rate of sub-3 $\mathrm{nm}$ particles in Beijing

Intensive NPF events with high formation rates are frequently observed in Beijing. The mean and median values of the daily maximum formation rates of $1.5 \mathrm{~nm}$ particles $\left(J_{\mathrm{C}, 10}\right)$ for this long-term dataset are 67 and $28 \mathrm{~cm}^{-3} \mathrm{~s}^{-1}$, respectively. $18 \%$ of the measured daily maximum formation rates exceed $100 \mathrm{~cm}^{-3} \mathrm{~s}^{-1}$ and one NPF event even has 
the $J_{\mathrm{C}, 10}$ value greater than $1000 \mathrm{~cm}^{-3} \mathrm{~s}^{-1}$. Calculated using the corrected appearance time method, the growth rates of sub-3 nm particles in Beijing are mostly below $6 \mathrm{~nm} / \mathrm{h}$ (Fig. 5). The mean and median $\mathrm{GR}_{1.5-3}$ values are 2.7 and 2.4 $\mathrm{nm} / \mathrm{h}$, respectively. These growth rates are not significantly different from those in the Finnish boreal forest ${ }^{47}$. However, the formation rates in Beijing are 1-2 orders of magnitude higher than those in clean environments ${ }^{2,48}$, which compensates the low survival of newly formed sub-3 nm particles in polluted urban environments.

\section{Summary}

The high concentration of background aerosols in megacities affects new particle formation in various aspects. This study quantitatively investigated these effects based on long-term atmospheric measurements (373 days) in urban Beijing. The median condensation sinks during these days and only new particle formation days were $0.03 \mathrm{~s}^{-1}$ and $0.009 \mathrm{~s}^{-1}$, respectively. This high concentration of background aerosols governs the survival of molecular clusters and newly formed sub-3 nm particles, thus the occurrence of new particle formation events. In Beijing, most new particle formation events occurred when condensation sink was below $0.03 \mathrm{~s}^{-1}$. When condensation sink increases, the concentrations of $\mathrm{H}_{2} \mathrm{SO}_{4}$-base clusters and sub-3 nm particles decrease significantly despite that the key nucleating acid and base precursors are at a similar level or even increase. During days without new particle formation events, the atmospheric residence time of sub-3 nm particles is usually below 5 min because of the high condensation sink with a median value of $0.045 \mathrm{~s}^{-1}$.

Despite of the high concentration of background aerosols, intensive new particle formation events driven by the acid-base nucleation happen frequently in Beijing. Among these 373 days, $47 \%$ of them were identified as new particle formation days and undefined days. The mean formation rate of $1.5 \mathrm{~nm}$ particles was $67 \mathrm{~cm}^{-3} \mathrm{~s}^{-1}$, which is more than one order of magnitude higher than that in clean environments. During these events, high concentrations of sub-3 nm particles were formed and they mostly range from $10^{3}$ to $10^{5} \mathrm{~cm}^{-3}$. The mean particle growth rate from $1.5 \mathrm{~nm}$ to $3 \mathrm{~nm}$ was $2.7 \mathrm{~nm} / \mathrm{h}$, which is not significantly different from that in clean environments. Although the high scavenging by background aerosols and the relatively low growth rate result in a low survival of newly formed particles, it is compensated by the high formation rates in Beijing.

In addition, we confirmed that improved methods should be used to quantify the formation rate and the growth rate of sub-3 $\mathrm{nm}$ particles when there is a strong coagulation scavenging due to background aerosols. The conventional balance formula underestimates the formation rate of $1.5 \mathrm{~nm}$ particles due to underestimating the coagulation sink term. The conventional appearance time method overestimates the grow rate of sub-3 nm particles because of mistaking the coagulation sink as the condensation growth.

\section{Acknowledgment}

Financial support from Beijing Outstanding Young Scientist Program (JJWZYJH01201910003010), National Key R\&D Program of China (2017YFC0209501), National Natural Science Foundation of China (21876094), Academy of Finland (332547), and Samsung PM P.5 $_{2.5}$ SR is acknowledged. 


\section{References}

1. M. Kulmala, H. Vehkamäki, T. Petäjä, M. Dal Maso, A. Lauri, V.-M. Kerminen, W. Birmili and P. H. McMurry, Journal of Aerosol Science, 2004, 35, 143-176.

2. V.-M. Kerminen, X. Chen, V. Vakkari, T. Petäjä, M. Kulmala and F. Bianchi, Environmental Research Letters, 2018, 13.

3. C. Kuang, P. H. McMurry and A. V. McCormick, Geophysical Research Letters, 2009, 36, L09822.

4. H. Gordon, J. Kirkby, U. Baltensperger, F. Bianchi, M. Breitenlechner, J. Curtius, A. Dias, J. Dommen, N. M. Donahue, E. M. Dunne, J. Duplissy, S. Ehrhart, R. C. Flagan, C. Frege, C. Fuchs, A. Hansel, C. R. Hoyle, M. Kulmala, A. Kürten, K. Lehtipalo, V. Makhmutov, U. Molteni, M. P. Rissanen, Y. Stozkhov, J. Tröstl, G. Tsagkogeorgas, R. Wagner, C. Williamson, D. Wimmer, P. M. Winkler, C. Yan and K. S. Carslaw, Journal of Geophysical Research: Atmospheres, 2017, 122, 8739-8760.

5. Z. Wu, M. Hu, S. Liu, B. Wehner, S. Bauer, A. Ma Bling, A. Wiedensohler, T. Petäjä, M. Dal Maso and M. Kulmala, Journal of Geophysical Research, 2007, 112, D09209.

6. Z. B. Wang, M. Hu, J. Y. Sun, Z. J. Wu, D. L. Yue, X. J. Shen, Y. M. Zhang, X. Y. Pei, Y. F. Cheng and A. Wiedensohler, Atmospheric Chemistry and Physics, 2013, 13, 12495-12506.

7. M. Dal Maso, M. Kulmala, I. Riipinen, R. Wagner, T. Hussein, P. Aalto and K. E. Lehtinen, Boreal Environment Research, 2005, 10, 323-336.

8. P. H. McMurry, Journal of Colloid and Interface Science, 1983, 95, 72-80.

9. M. Kulmala, M. Dal Maso, J. M. Mäkelä, L. Pirjola, M. Väkevä, P. Aalto, P. Miikkulainen, K. Hämeri and C. D. O'dowd, Tellus, 2001, 53, 479-490.

10. P. H. McMurry, M. Fink, H. Sakurai, M. R. Stolzenburg, R. L. Mauldin, J. Smith, F. Eisele, K. Moore, S. Sjostedt, D. Tanner, L. G. Huey, J. B. Nowak, E. Edgerton and D. Voisin, Journal of Geophysical Research, 2005, 110, D22S02.

11. R. J. Weber, J. J. Marti, P. H. McMurry, F. L. Eisele, D. J. Tanner and A. Jefferson, Journal of Geophysical Research: Atmospheres, 1997, 102, 4375-4385.

12. V. M. Kerminen and M. Kulmala, Journal of Aerosol Science, 2002, 33, 609-622.

13. C. Kuang, I. Riipinen, S. L. Sihto, M. Kulmala, A. V. McCormick and P. H. McMurry, Atmospheric Chemistry and Physics, 2010, 10, 8469-8480.

14. J. Jiang, M. Chen, C. Kuang, M. Attoui and P. H. McMurry, Aerosol Science and Technology, 2011, 45, 510521.

15. J. Jiang, J. Zhao, M. Chen, F. L. Eisele, J. Scheckman, B. J. Williams, C. Kuang and P. H. McMurry, Aerosol Science and Technology, 2011, 45, ii-v.

16. R. Cai, D.-R. Chen, J. Hao and J. Jiang, Journal of Aerosol Science, 2017, 106, 111-119.

17. J. Kangasluoma, R. Cai, J. Jiang, C. Deng, D. Stolzenburg, L. R. Ahonen, T. Chan, Y. Fu, C. Kim, T. M. Laurila, Y. Zhou, L. Dada, J. Sulo, R. C. Flagan, M. Kulmala, T. Petäjä and K. Lehtipalo, Journal of Aerosol Science, 2020, 148, 105584.

18. R. Cai and J. Jiang, Atmospheric Chemistry and Physics, 2017, 17, 12659-12675.

19. R. Cai, D. Yang, Y. Fu, X. Wang, X. Li, Y. Ma, J. Hao, J. Zheng and J. Jiang, Atmospheric Chemistry and Physics, 2017, 17, 12327-12340.

20. C. Deng, Y. Fu, L. Dada, C. Yan, R. Cai, D. Yang, Y. Zhou, R. Yin, Y. Lu, X. Li, X. Qiao, X. Fan, W. Nie, J. Kontkanen, J. Kangasluoma, B. Chu, A. Ding, V. Kerminen, P. Paasonen, R. D. Worsnop, F. Bianchi, Y. Liu, J. Zheng, L. Wang, M. Kulmala and J. Jiang, Environmental Science and Technology, 2020, DOI: 10.1021/acs.est.0c00808.

21. R. Cai, I. Chandra, D. Yang, L. Yao, Y. Fu, X. Li, Y. Lu, L. Luo, J. Hao, Y. Ma, L. Wang, J. Zheng, T. Seto and J. 
Jiang, Atmospheric Chemistry and Physics, 2018, 18, 16587-16599.

R. Cai, D. Yang, R. Yin, C. Yan, J. Zheng, K. Markku and J. Jiang, under review, 2020.

23. R. Cai, C. Li, X.-C. He, C. Deng, Y. Lu, R. Yin, C. Yan, L. Wang, J. Jiang, M. Kulmala and J. Kangasluoma, Atmospheric Chemistry and Physics Discussions, 2020, DOI: 10.5194/acp-2020-398.

24. A. Kürten, C. Li, F. Bianchi, J. Curtius, A. Dias, N. M. Donahue, J. Duplissy, R. C. Flagan, J. Hakala, T. Jokinen, J. Kirkby, M. Kulmala, A. Laaksonen, K. Lehtipalo, V. Makhmutov, A. Onnela, M. P. Rissanen, M. Simon, M. Sipilä, Y. Stozhkov, J. Tröstl, P. Ye and P. H. McMurry, Atmospheric Chemistry and Physics, 2018, 18, 845863.

25. Y. Lu, C. Yan, Y. Fu, Y. Chen, Y. Liu, G. Yang, Y. Wang, F. Bianchi, B. Chu, Y. Zhou, R. Yin, R. Baalbaki, O. Garmash, C. Deng, W. Wang, Y. Liu, T. Petäjä, V.-M. Kerminen, J. Jiang, M. Kulmala and L. Wang, Atmospheric Chemistry and Physics, 2019, 19, 1971-1983.

26. J. Liu, J. Jiang, Q. Zhang, J. Deng and J. Hao, Frontiers of Environmental Science \& Engineering, 2016, 10, 63-72.

27. R. Cai, Y. Zhou and J. Jiang, Aerosol Science and Technology, 2019, 54, 21-32.

28. Y. Fu, M. Xue, R. Cai, J. Kangasluoma and J. Jiang, Aerosol Science and Technology, 2019, 53, 793-801.

29. J. Zheng, D. Yang, Y. Ma, M. Chen, J. Cheng, S. Li and M. Wang, Atmospheric Environment, 2015, 119, $167-$ 173.

30. J. Jiang, W. Zhou, Z. Cheng, S. Wang, K. He and J. Hao, Aerosol and Air Quality Research, 2015, 15, 494503.

31. T. Anttila, V.-M. Kerminen and K. E. J. Lehtinen, Journal of Aerosol Science, 2010, 41, 621-636.

32. B. K. Ku and J. F. de la Mora, Aerosol Science and Technology, 2009, 43, 241-249.

33. C. Larriba, C. J. Hogan, M. Attoui, R. Borrajo, J. F. Garcia and J. F. de la Mora, Aerosol Science and Technology, 2011, 45, 453-467.

34. K. E. J. Lehtinen, M. Dal Maso, M. Kulmala and V.-M. Kerminen, Journal of Aerosol Science, 2007, 38, 988994.

35. R. Zhang, A. Khalizov, L. Wang, M. Hu and W. Xu, Chemical Reviews, 2012, 112, 1957-2011.

36. A. Kürten, T. Jokinen, M. Simon, M. Sipila, N. Sarnela, H. Junninen, A. Adamov, J. Almeida, A. Amorim, F. Bianchi, M. Breitenlechner, J. Dommen, N. M. Donahue, J. Duplissy, S. Ehrhart, R. C. Flagan, A. Franchin, J. Hakala, A. Hansel, M. Heinritzi, M. Hutterli, J. Kangasluoma, J. Kirkby, A. Laaksonen, K. Lehtipalo, M. Leiminger, V. Makhmutov, S. Mathot, A. Onnela, T. Petaja, A. P. Praplan, F. Riccobono, M. P. Rissanen, L. Rondo, S. Schobesberger, J. H. Seinfeld, G. Steiner, A. Tome, J. Trostl, P. M. Winkler, C. Williamson, D. Wimmer, P. Ye, U. Baltensperger, K. S. Carslaw, M. Kulmala, D. R. Worsnop and J. Curtius, Proceedings of the National Academy of Sciences of the United States of America, 2014, 111, 15019-15024.

37. F. Bianchi, A. P. Praplan, N. Sarnela, J. Dommen, A. Kurten, I. K. Ortega, S. Schobesberger, H. Junninen, M. Simon, J. Trostl, T. Jokinen, M. Sipila, A. Adamov, A. Amorim, J. Almeida, M. Breitenlechner, J. Duplissy, S. Ehrhart, R. C. Flagan, A. Franchin, J. Hakala, A. Hansel, M. Heinritzi, J. Kangasluoma, H. Keskinen, J. Kim, J. Kirkby, A. Laaksonen, M. J. Lawler, K. Lehtipalo, M. Leiminger, V. Makhmutov, S. Mathot, A. Onnela, T. Petaja, F. Riccobono, M. P. Rissanen, L. Rondo, A. Tome, A. Virtanen, Y. Viisanen, C. Williamson, D. Wimmer, P. M. Winkler, P. Ye, J. Curtius, M. Kulmala, D. R. Worsnop, N. M. Donahue and U. Baltensperger, Environ Sci Technol, 2014, 48, 13675-13684.

38. N. Myllys, J. Kubečka, V. Besel, D. Alfaouri, T. Olenius, J. N. Smith and M. Passananti, Atmospheric Chemistry and Physics, 2019, 19, 9753-9768.

39. L. Yao, O. Garmash, F. Bianchi, J. Zheng, C. Yan, J. Kontkanen, H. Junninen, S. B. Mazon, M. Ehn, P. Paasonen, M. Sipilä, M. Wang, X. Wang, S. Xiao, H. Chen, Y. Lu, B. Zhang, D. Wang, Q. Fu, F. Geng, L. Li, H. Wang, L. 
Qiao, X. Yang, J. Chen, V.-M. Kerminen, T. Petäjä, D. R. Worsnop, M. Kulmala and L. Wang, Science, 2018, $361,278-281$.

40. J. Almeida, S. Schobesberger, A. Kurten, I. K. Ortega, O. Kupiainen-Maatta, A. P. Praplan, A. Adamov, A. Amorim, F. Bianchi, M. Breitenlechner, A. David, J. Dommen, N. M. Donahue, A. Downard, E. Dunne, J. Duplissy, S. Ehrhart, R. C. Flagan, A. Franchin, R. Guida, J. Hakala, A. Hansel, M. Heinritzi, H. Henschel, T. Jokinen, H. Junninen, M. Kajos, J. Kangasluoma, H. Keskinen, A. Kupc, T. Kurten, A. N. Kvashin, A. Laaksonen, K. Lehtipalo, M. Leiminger, J. Leppa, V. Loukonen, V. Makhmutov, S. Mathot, M. J. McGrath, T. Nieminen, T. Olenius, A. Onnela, T. Petaja, F. Riccobono, I. Riipinen, M. Rissanen, L. Rondo, T. Ruuskanen, F. D. Santos, N. Sarnela, S. Schallhart, R. Schnitzhofer, J. H. Seinfeld, M. Simon, M. Sipila, Y. Stozhkov, F. Stratmann, A. Tome, J. Trostl, G. Tsagkogeorgas, P. Vaattovaara, Y. Viisanen, A. Virtanen, A. Vrtala, P. E. Wagner, E. Weingartner, H. Wex, C. Williamson, D. Wimmer, P. Ye, T. Yli-Juuti, K. S. Carslaw, M. Kulmala, J. Curtius, U. Baltensperger, D. R. Worsnop, H. Vehkamaki and J. Kirkby, Nature, 2013, 502, 359-363.

41. C. N. Jen, D. R. Hanson and P. H. McMurry, Aerosol Science and Technology, 2015, 49, i-iii.

42. J. Kontkanen, K. Lehtipalo, L. Ahonen, J. Kangasluoma, H. E. Manninen, J. Hakala, C. Rose, K. Sellegri, S. Xiao, L. Wang, X. Qi, W. Nie, A. Ding, H. Yu, S. Lee, V.-M. Kerminen, T. Petäjä and M. Kulmala, Atmospheric Chemistry and Physics, 2017, 17, 2163-2187.

43. M. Kulmala, T. Petäjä, T. Nieminen, M. Sipilä, H. E. Manninen, K. Lehtipalo, M. Dal Maso, P. P. Aalto, H. Junninen, P. Paasonen, I. Riipinen, K. E. Lehtinen, A. Laaksonen and V. M. Kerminen, Nature protoco/s, 2012, 7, 1651-1667.

44. K. Lehtipalo, J. Leppä, J. Kontkanen, J. Kangasluoma, A. Franchin, D. Wimmer, S. Schobesberger, H. Junninen, T. Petäjä, M. Sipilä, J. Mikkilä, J. Vanhanen, D. R. Worsnop and M. Kulmala, Boreal Environment Research, 2014, 19, 215-236.

45. W. Birmili, A. Wiedensohler, J. Heintzenberg and K. Lehmann, Journal of Geophysical Research: Atmospheres, 2001, 106, 32005-32018.

46. L. Dada, K. Lehtipalo, J. Kontkanen, T. Nieminen, R. Baalbaki, L. Ahonen, J. Duplissy, C. Yan, B. Chu, T. Petaja, K. Lehtinen, V. M. Kerminen, M. Kulmala and J. Kangasluoma, Nature protocols, 2020, 15, 1013-1040.

47. M. Vana, K. Komsaare, U. Horrak, S. Mirme, T. Nieminen, J. Kontkanen, H. E. Manninen, T. Petäjä, S. M. Noe and M. Kulmala, Boreal Environment Research, 2016, 21, 345-362.

48. M. Kulmala, J. Kontkanen, H. Junninen, K. Lehtipalo, H. E. Manninen, T. Nieminen, T. Petäjä, M. Sipilä, S. Schobesberger, P. Rantala, A. Franchin, T. Jokinen, E. Jarvinen, M. Äijälä, J. Kangasluoma, J. Hakala, P. P. Aalto, P. Paasonen, J. Mikkilä, J. Vanhanen, J. Aalto, H. Hakola, U. Makkonen, T. Ruuskanen, R. L. Mauldin, 3rd, J. Duplissy, H. Vehkamäki, J. Bäck, A. Kortelainen, I. Riipinen, T. Kurtén, M. V. Johnston, J. N. Smith, M. Ehn, T. F. Mentel, K. E. Lehtinen, A. Laaksonen, V.-M. Kerminen and D. R. Worsnop, Science, 2013, 339, 943-946. 


\section{Figures}
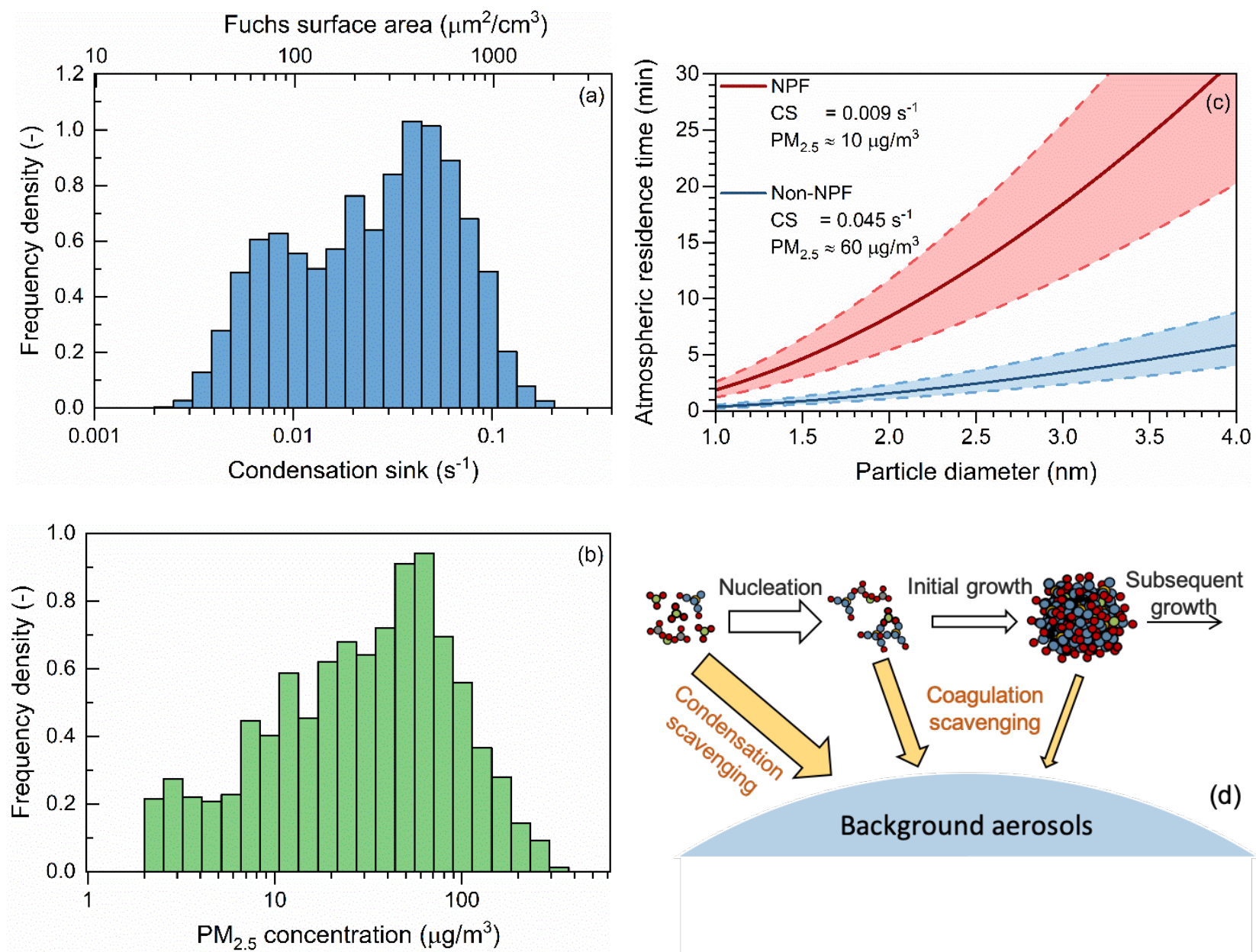

Figure 1. Formation and growth of new particles in the presence of the high background aerosol concentration in megacities such as Beijing. (a) Frequency density of condensation sink (CS) with a temporal resolution of 5 min during the measurement period (373 days) in Beijing, where the total area of the columns is 1 . The value of CS was calculated using measured size distributions of particles down to $\sim 1.3 \mathrm{~nm}$. (b) Frequency density of $\mathrm{PM}_{2.5}$ mass concentration with a temporal resolution of $1 \mathrm{~h}$ during the 373 days in Beijing, where the total area of the columns is 1. (c) Atmospheric residence time of particles as a function of their size under the real atmosphere CS values for NPF days and non-NPF days, respectively, in Beijing. Only the data during 9:00 - 14:00 are used in (a), (b), and (c). The residence time herein refers to the period needed for the concentration of a given aerosol population to decay to $1 / \mathrm{e}$ of its initial value due to the coagulation scavenging by background aerosols larger than the given aerosols, while particle growth is not considered. The solid lines show the median CS on NPF and non-NPF days. The shaded areas between dashed lines indicate the residence time of aerosol under the $25^{\text {th }}$ (lower) and $75^{\text {th }}$ (upper) percentiles of CS. The $25^{\text {th }}$ and $75^{\text {th }}$ percentiles of CS are 0.006 and $0.13 \mathrm{~s}^{-1}$ on NPF days, and 0.027 and $0.064 \mathrm{~s}^{-1}$ on non-NPF days. (d) A conceptual figure for the scavenging of gaseous precursors, clusters and particles by background aerosols during nucleation and growth processes. 

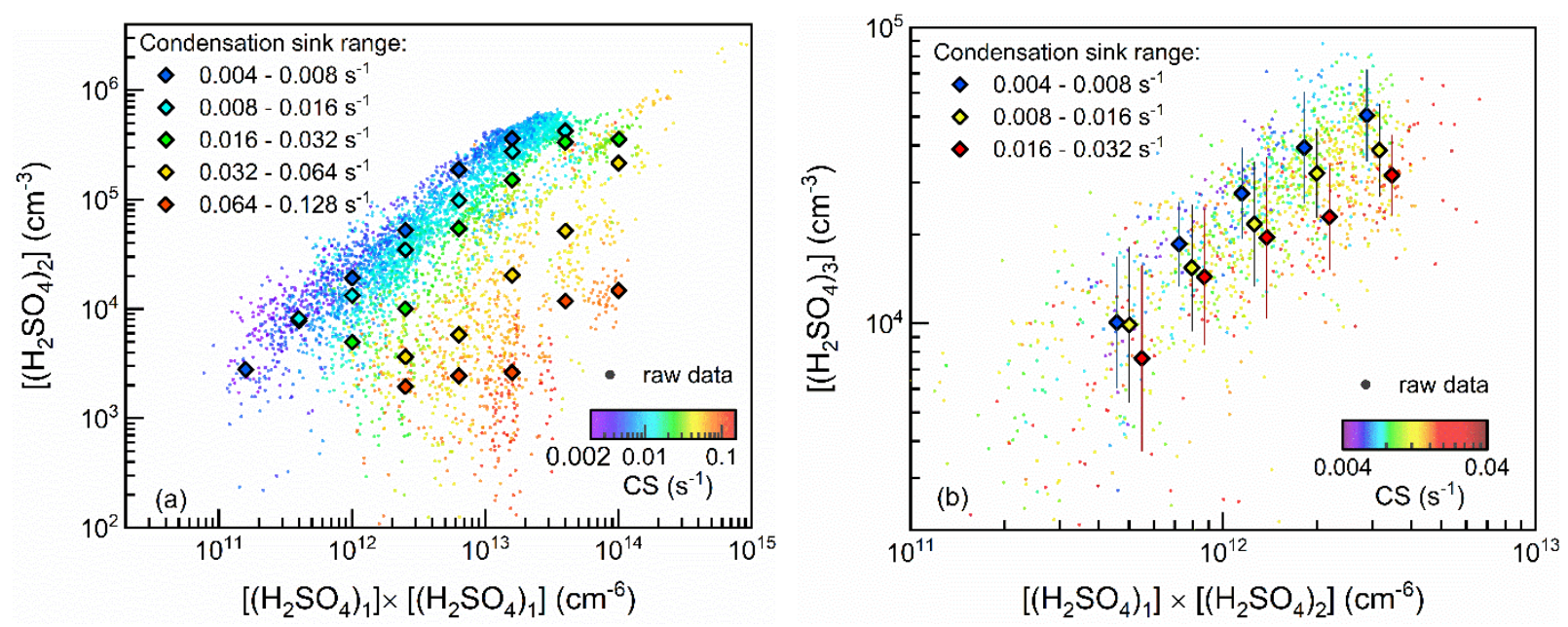

Figure 2. Influence of the condensation sink (CS) on the concentrations of $\mathrm{H}_{2} \mathrm{SO}_{4}$ dimers (a) and trimers (b). $\mathrm{A}_{2} \mathrm{SO}_{4}$ dimer or trimer refers to a cluster containing two or three $\mathrm{H}_{2} \mathrm{SO}_{4}$ molecules and any number of other molecules. The subscript of $\left(\mathrm{H}_{2} \mathrm{SO}_{4}\right)$ indicates the number of $\mathrm{H}_{2} \mathrm{SO}_{4}$ molecules containted in each $\mathrm{H}_{2} \mathrm{SO}_{4}$ cluster/molecule. The circles are the raw data with a 5-min time resolution. The horizontal axis of (a) and (b) is proporational to the production rate of $\mathrm{H}_{2} \mathrm{SO}_{4}$ dimers and trimers, respectively. The diamond markers and the vertical lines denote the geometric mean concentrations grouped by the horizontal variables and their corresponding geometric standard deviations. 


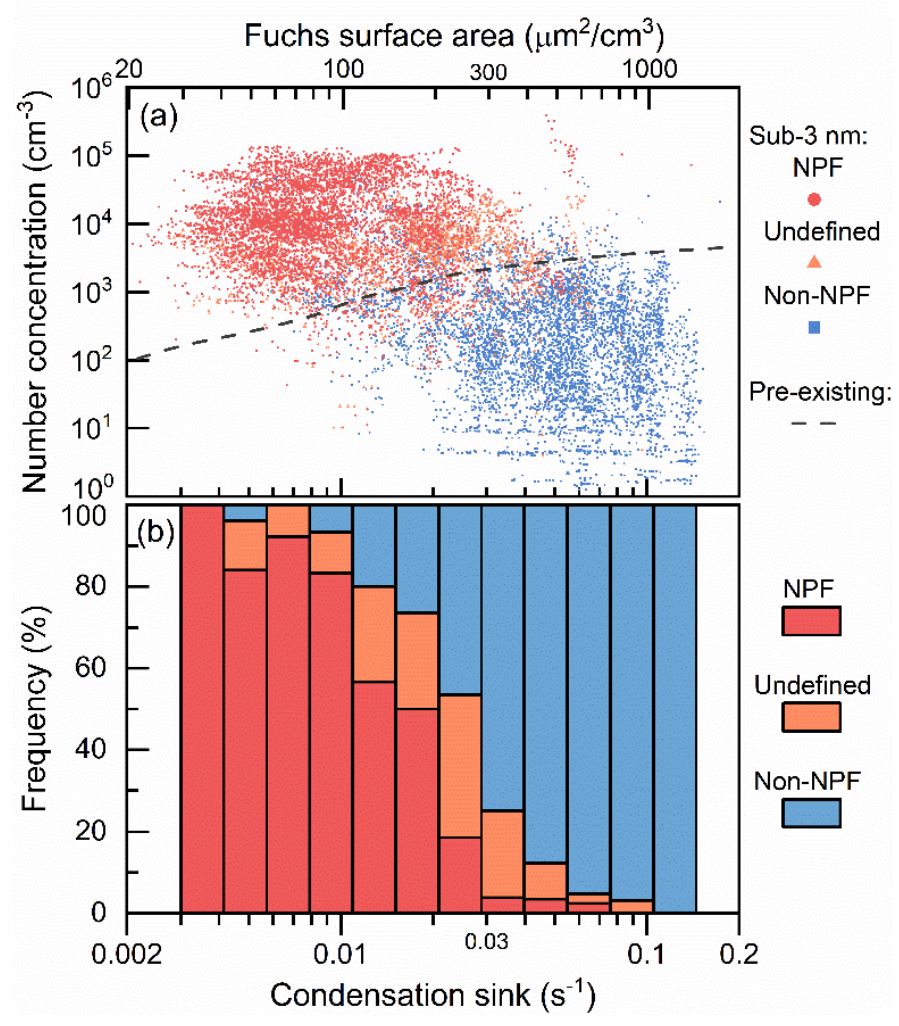

Figure 3. (a) The number concentrations of sub-3 nm particles and (b) the frequencies of NPF, undefined and nonNPF days under different condensation sink values in urban Beijing. The Fuchs surface area is also as a horizontal axis and its ratio to the condensation sink is approximately equal to a constant ${ }^{10}$. The dash line in (a) represents the $10^{\text {th }}$ percentile of sub- $25 \mathrm{~nm}$ aerosol concentrations during non-NPF periods on both NPF and non-NPF days in each condensation sink bin. The temporal resolution of the data shown in (a) is 5 min while the average condensation sink during 9:00 - 14:00 is used in (b). Due to the averaging, the measured condensation sink in (b) spans over a narrower range than that in (a). Only the data between 9:00 and 14:00 is used because nucleation usually occurs around noon when $\mathrm{H}_{2} \mathrm{SO}_{4}$ concentration is around its daily maximum. 

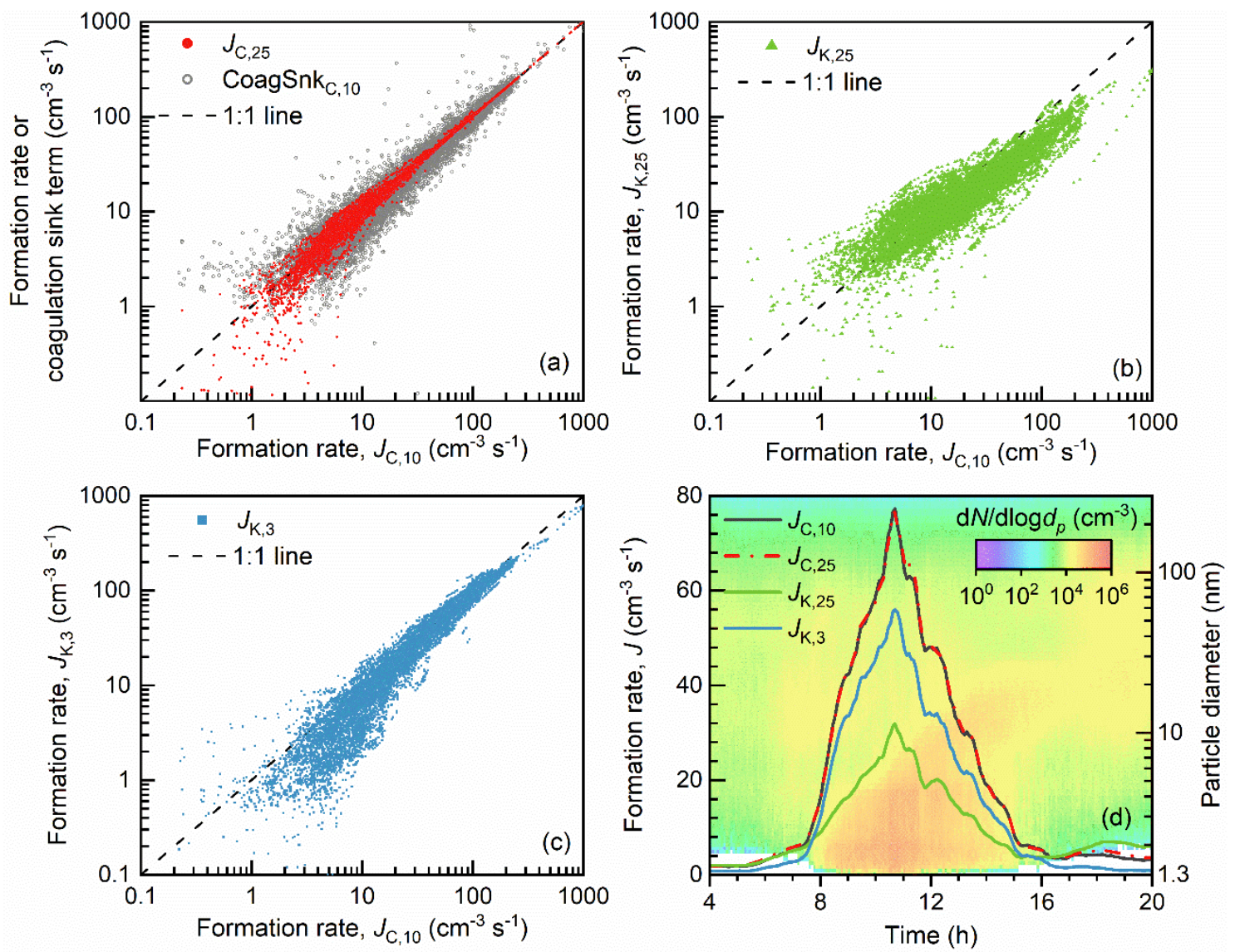

Figure 4. The comparison between formation rates of $1.5 \mathrm{~nm}$ particles calculated using the conventional balance formula $\left(J_{\mathrm{K}}\right)$ and using the improved formula $\left(J_{\mathrm{C}}\right)$. Note that the numbers in the subscript of $J$ indicate the upper limit of the chosen size range for the population balance assumption. CoagSnk $\mathrm{C}_{\mathrm{C}, 10}$ denotes the coagulation sink term for estimating $J_{\mathrm{C}, 10}$. Only the formation rates during NPF periods (identified for each event) are presented in (a), (b) and (c). The aerosol size distributions shown in (d) are the median distributions on intensive new particle formation days with daily maximum $J_{\mathrm{C}, 10}$ exceeding $50 \mathrm{~cm}^{-3} \mathrm{~s}^{-1}$. The formation rates in (d) were calculated based on these median distributions. 


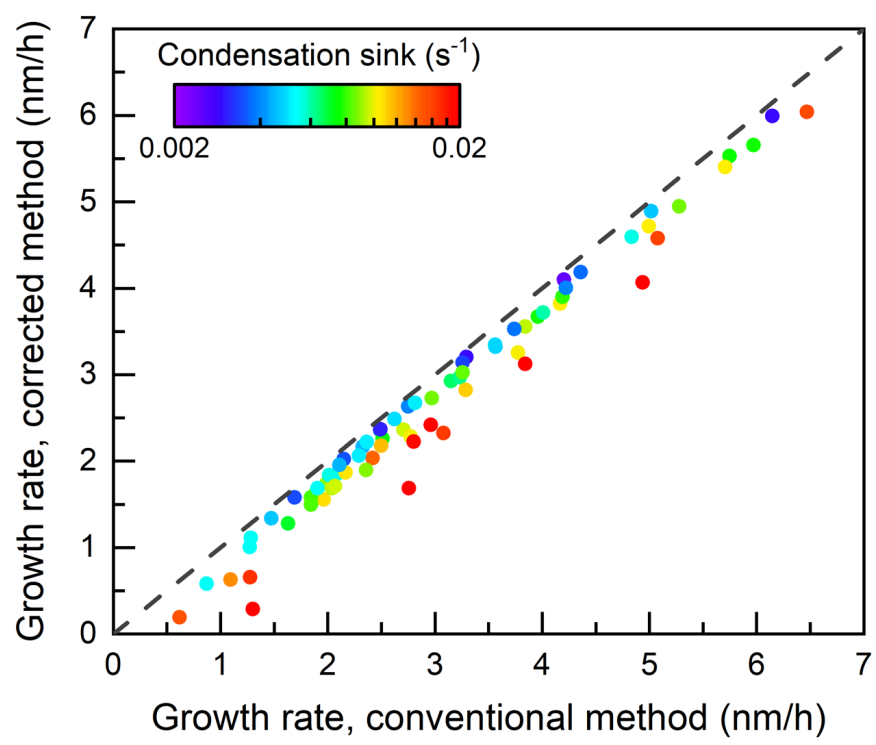

Figure 5. The comparison between particle growth rates from $1.5 \mathrm{~nm}$ to $3 \mathrm{~nm}\left(\mathrm{GR}_{1.5-3}\right)$ calculated using the conventional and corrected appearance time methods. $\mathrm{GR}_{1.5-3}$ was determined as the harmonic mean of sizesegregated growth rates ranging from 1.5 to $3 \mathrm{~nm}$. The NPF days on which the measured temporal evolution of aerosol size distributions was significantly influenced by other sources or sinks, e.g. primary emissions and transport, were excluded. The colors indicate the mean condensation sink between the time when $50 \%$ of the maximum concentration of $1.5 \mathrm{~nm}$ particles was reached and when $50 \%$ of the maximum concentration of $3 \mathrm{~nm}$ particles was reached. The dashed line is a 1:1 line to guide eyes. 